\title{
Impacto do PIBIC-Ensino Médio na escolha profissional
}

\author{
Impacto of IPSIS-High School on professional choice \\ Impacto del PIBIC-Escuela Secundaria en la elección profesional
}

Recebido: 15/10/2021 | Revisado: 24/10/2021 | Aceito: 28/10/2021 | Publicado: 30/10/2021

Erika Danielle Ribeiro Dourado

ORCID: https://orcid.org/0000-0002-3797-2474

Universidade do Estado do Pará, Brasil

E-mail: erika.dourado@aluno.uepa.br

Igor Costa de Lima

ORCID: https://orcid.org/0000-0002-3773-7319 Universidade do Estado do Pará, Brasil Instituto Evandro Chagas, Brasil

E-mail: igor.cdlima@ aluno.uepa.br

Anderson Bentes de Lima

ORCID: https://orcid.org/0000-0002-0534-2654 Universidade do Estado do Pará, Brasil E-mail: andersonbentes@uepa.br

Robson José de Souza Domingues

ORCID: https://orcid.org/0000-0001-5419-2878 Universidade do Estado do Pará, Brasi E-mail: domingues@uepa.br Kátia Simone Kietzer

ORCID: https://orcid.org/0000-0001-6992-3557 Universidade do Estado do Pará, Brasil E-mail: katia.kietzer@uepa.br Jofre Jacob da Silva Freitas

ORCID: https://orcid.org/0000-0002-0568-7177 Universidade do Estado do Pará, Brasil E-mail: jofre.freitas@uepa.br

Fabíola Raquel Tenório Oliveira

ORCID: https://orcid.org/0000-0001-7017-5517 Universidade do Estado do Pará, Brasil E-mail: fabiola.tenorio@uepa.br

\begin{abstract}
Resumo
O Programa Institucional de Bolsas de Iniciação Científica para o Ensino Médio objetiva despertar a vocação científica e descobrir novos talentos. Este programa vem sendo discutido por autores sobre diferentes pontos de vista, e este estudo transversal busca analisar quali-quantitativamente o impacto do programa, sobre a escolha profissional dos participantes, relacionando a participação no mesmo e a escolha pela formação na área de Ciências Biológicas e da Saúde, identificando o nível e as características atuais de formação desses ex-alunos e a relação da experiência com o ensino superior, desenvolvido no laboratório de Morfofisiologia aplicado à saúde da Universidade do Estado do Pará (UEPA) no ano de 2011. Foi realizada uma pesquisa de campo exploratória, em seguida foram entrevistados 15 ex-alunos através de um questionário do Formulário Google, com perguntas abertas e fechadas. A análise da estatística descritiva obtida a partir dos dados organizados no Excel revelou que a maioria dos indivíduos possuía baixa renda, alcançaram o ensino superior em instituições de ensino públicas e seguiram carreira na área de Ciências Biológicas e da Saúde. Em relação à análise qualitativa, a maioria dos participantes alega a relevante importância do programa para suas escolhas profissionais e para o crescimento pessoal. Nesse sentido, o trabalho confirma o mérito de Programas como o PIBIC-EM. e reforça a necessidade de haver mais investimentos para a continuidade desse importante Programa.
\end{abstract}

Palavras-chave: Pesquisa científica; Eficácia do programa; Escolha de carreira.

\begin{abstract}
The Institutional Program for Scientific Initiation Scholarships for High Schools (IPSIS-HS) aims to awaken the scientific vocation and discover new talents. This program has been discussed by authors from different points of view, and this cross-sectional study seeks to qualitatively and quantitatively analyze the impact of the program on the professional choice of participants, relating their participation in it and the choice of training in the area of Biological Sciences and of Health, identifying the level and current characteristics of training of these former students and the relationship of experience with higher education, developed in the Morphophysiology laboratory applied to health at the University of the State of Pará (USPA) in 2011. It was carried out an exploratory field research, then 15 former students were interviewed through a Google Form questionnaire, with open and closed questions. The analysis of
\end{abstract}


descriptive statistics obtained from the data organized in Excel revealed that most individuals had low income, attained higher education in public educational institutions and pursued a career in the area of Biological and Health Sciences. Regarding the qualitative analysis, most participants allege the program's relevant importance for their professional choices and personal growth. In this sense, the work confirms the merit of Programs such as IPSIS-HS and reinforces the need for more investments for the continuity of this important Program.

Keywords: Scientific research, Program effectiveness, Career choice.

\section{Resumen}

El Programa Institucional de Becas de Iniciación Científica para la Escuela Secundaria (PIBIC-ES) tiene como objetivo despertar la vocación científica y descubrir nuevos talentos. Este programa ha sido discutido por autores desde diferentes puntos de vista, y este estudio transversal busca analizar cualitativa y cuantitativamente el impacto del programa en la elección profesional de los participantes, relacionando su participación en el mismo y la elección de la formación en el área. de Ciencias Biológicas y de la Salud, identificando el nivel y características actuales de formación de estos exalumnos y la relación de la experiencia con la educación superior, desarrollada en el laboratorio de Morfofisiología aplicada a la salud de la Universidad del Estado de Pará (UEPA) en 2011. Se realizó una investigación de campo exploratoria, luego se entrevistó a 15 exalumnos a través de un cuestionario Google Form, con preguntas abiertas y cerradas. El análisis de las estadísticas descriptivas obtenidas a partir de los datos// organizados en Excel reveló que la mayoría de las personas tenían bajos ingresos, cursaron estudios superiores en instituciones educativas públicas y realizaron una carrera en el área de Ciencias Biológicas y de la Salud. Respecto al análisis cualitativo, la mayoría de los participantes alega la importancia relevante del programa para sus elecciones profesionales y crecimiento personal. En este sentido, el trabajo confirma el mérito de Programas como PIBIC-ES y refuerza la necesidad de más inversiones para la continuidad de este importante Programa.

Palabras clave: Investigación científica; Efectividad del programa; Elección de carrera.

\section{Introdução}

O Conselho Nacional de Desenvolvimento Científico e Tecnológico (CNPq) fornece bolsas para estudo e pesquisa no Brasil desde 1951, e segundo Conceição (2012), com o objetivo de proporcionar e aguçar a extensão científica e tecnológica em qualquer âmbito do saber. Em 1988, foi criado o Programa Institucional de Bolsas de Iniciação Científica (PIBIC), objetivando incentivar talentos entre os graduandos e articular a graduação com a pós-graduação (Massi \& Queiroz, 2010).

A participação de estudantes em atividades de pesquisa foi oficializada pela Lei n. 10.172/01 (2001), cuja finalidade é: "Incentivar a generalização da prática de pesquisa como elemento integrante e modernizador do processo de ensino e aprendizagem em toda a educação superior, inclusive com a participação de alunos no desenvolvimento da pesquisa" (Lei n. 10.172/01, 2001).

O CNPq concede bolsa na modalidade Iniciação Científica Júnior (ICJ), desde 2003, para alunos do ensino médio e profissional de instituições públicas de ensino, normativa n.017/2006 (CNPq, 2006). Com o intuito de despertar a vocação científica, o CNPq estendeu a abrangência do programa para o ensino fundamental, no final de 2008 (Santos, 2011).

Amparada pela Lei Complementar n. 061, de 24 de julho (2007), a Fundação Amazônia de Amparo a Estudos e Pesquisas do Pará (FAPESPA) lança desde 2008, no estado, editais de concessão de bolsas através do Programa Institucional de Bolsas de Iniciação Científica Junior (PIBIC Jr.) cujo foco é a realização de pesquisas sob orientação individualizada em ambientes de produção de conhecimentos científicos como Institutos, Universidades e Centros de Pesquisa (Lei n.061, 2007).

Segundo Conceição (2012), há três programas de ICJ vigentes, a própria ICJ conjuntamente às Fundações estaduais de Amparo à Pesquisas (FAPs), o PIBIC voltado para o EM (PIBIC-EM) e o Programa de Iniciação Científica designada à alunos aprovados para a Olimpíada Brasileira de Matemática das Escolas Públicas (PIC-OBMEP). Esses programas possuem os mesmos objetivos em comum, que consistem em aproximar os alunos dos métodos científicos, estimulando o interesse pela pesquisa.

A Iniciação Científica (IC), tanto ao nível de graduação, quanto de educação básica, ocorre sob a prerrogativa de incentivo à vocação e novos talentos para a pesquisa (Santos, 2011). Dentro desse contexto, a inserção de jovens no meio 
acadêmico-científico através das bolsas do PIBIC-Ensino Médio (PIBIC-EM) representa a quebra do distanciamento existente entre a Educação Básica (EB) e o Ensino Superior (ES).

No programa de PIBIC-EM o aluno tem a oportunidade de conhecer laboratórios, colaborar com alguns experimentos, treinar na busca de informações em bases de dados científicas, aprimorar língua estrangeria, além de interagir com os alunos e professores da graduação e conhecer melhor as profissões da área onde está inserido no estágio.

A aproximação entre o Ensino Básico e a Ensino Superior promove melhoras na permanência dos alunos nas escolas públicas, incentiva o apreço pela ciência e o desenvolvimento de talentos científicos (Oliveira \& Bianchetti, 2018; Melo, 2020) e, portanto, o PIBIC-EM. é uma ferramenta essencial para a formação de cidadãos críticos e aptos ao desenvolvimento científico, mas que ainda possui pouca visibilidade (Moraes, Soppa, Umbelino, \& Vieira, 2013).

Ao final da participação no PIBIC-EM., alguns questionamentos podem surgir, tais como: Qual o impacto da participação desses jovens no Programa para a escolha da carreira profissional? Qual a relevância para que eles optassem por fazer uma graduação? Esses jovens optaram pela área de Ciências Biológicas e da Saúde? Esses objetivos foram atingidos?

Dessa forma o artigo busca avaliar o impacto do PIBIC-EM na escolha profissional de ex-alunos bolsistas do Programa que participaram do edital N 011/2010 (Pará, 2010) e desenvolveram atividades no Laboratório de Morfofisiologia Aplicada à Saúde da Universidade do Estado do Pará (UEPA), no ano de 2011, relacionando a participação no programa com a escolha pela formação na área de Ciências Biológicas e da Saúde, identificando o nível e as características atuais de formação desses ex-alunos e a relação da experiência com o ensino superior.

O estudo transversal de abordagem quali-quantitativa de escala local se baseia no uso da estatística descritiva. Os resultados apontam para a correlação da participação no PIBIC-EM com os fatores: renda familiar no período de participação do programa, participação em outras atividades acadêmico-científicas, nível de formação atual, tipos de instituições de ES que foram cursadas e importância do contato do ensino básico com o meio acadêmico.

\section{Metodologia}

\subsection{Tipo de estudo}

Trata-se de um estudo transversal, qualitativo-quantitativo e exploratório com busca ativa dos participantes PIBICEM, seguindo a proposta de Pereira et al. (2018) para esse tipo de estudo, utilizando-se questionários com perguntas abertas e fechadas.

\subsection{Aspectos éticos}

Este trabalho foi aprovado pelo Comitê de Ética em Pesquisa (CEP) parecer de aprovação 3.901.296. Para participarem desta pesquisa, os participantes tiveram acesso ao Termo de Consentimento Livre e Esclarecido (TCLE) aplicado virtualmente através de formulários do Google hospedado na plataforma Google, respeitando os aspectos de confidencialidade dos dados que foram coletados.

\subsection{Amostras}

No edital $N^{\circ}$ 011/2010 (Pará, 2010) foram aprovados 26 alunos bolsistas, destes 15 aceitaram participar da pesquisa por meio de um questionário virtual. Os participantes desenvolveram as atividades do programa, relativas à morfofisiologia humana, no Laboratório de Morfofisiologia Aplicada à Saúde da UEPA.

Os dados dos participantes, como nomes, números de telefone, e-mails foram fornecidos pelos professores exorientadores a partir de seus arquivos pessoais, acompanhados de carta de concessão de dados devidamente assinada por todos. 
Diante da constatação de dados obsoletos (números telefônicos e e-mails), em face do alargado período desde a realização do programa, há aproximadamente 10 anos, os contatos foram realizados também por meio de redes sociais. Vale ressaltar que foi feita a busca dos 26 alunos, contudo, alguns não foram encontrados e outros não aceitaram participar.

\subsection{Coleta e análise de dados}

O questionário da pesquisa teve 7 perguntas fechadas e 4 abertas. Foi aplicado no período de maio a junho de 2020 , para 15 indivíduos ex-alunos do Programa, via e-mail através do Formulário Google, apresentando quatro perguntas pessoais e sete perguntas gerais, relacionadas ao impacto do PIBIC-EM. na escolha profissional.

A análise foi realizada a partir de dados coletados pelo preenchimento do formulário, contendo duas etapas, sendo: (1) informações pessoais do participante (nome, idade, contato e renda familiar no período de participação no programa); e, (2) referente à participação dos alunos no programa e carreira profissional atual - Questionário Principal. Todas as fases do trabalho podem ser observadas na Figura 1.

Figura 1. Fluxograma do resumo metodológico aplicado na presente pesquisa

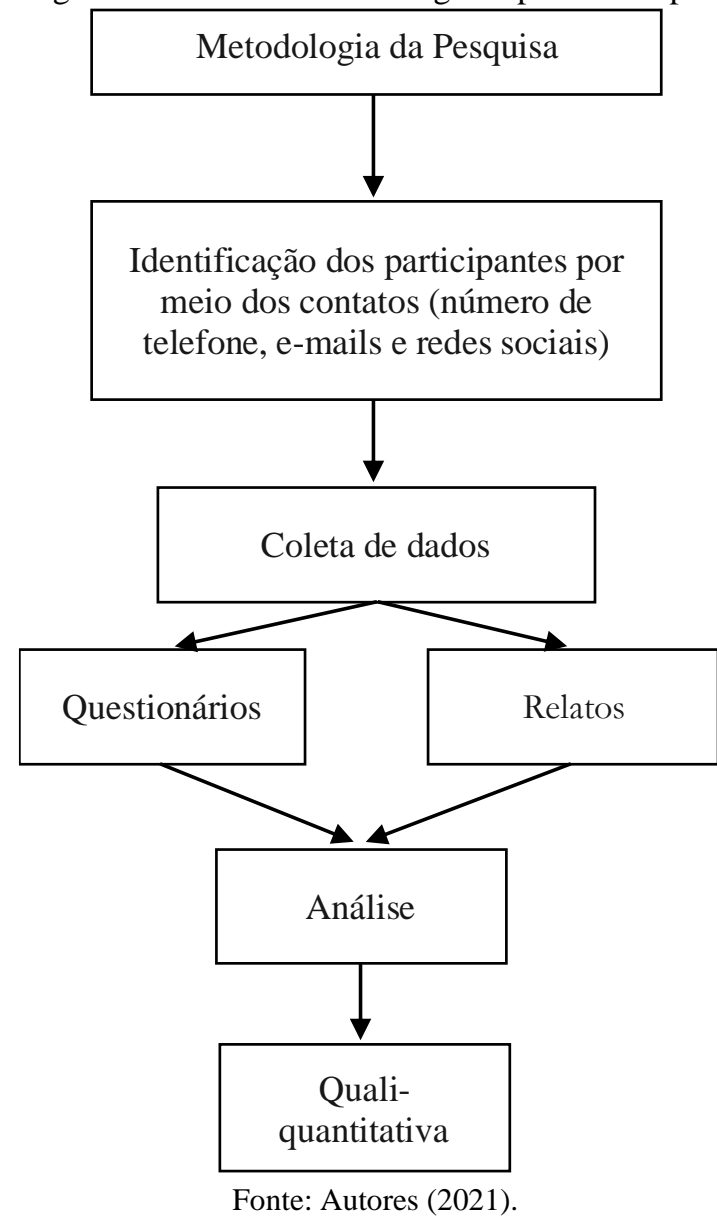

Para realizar a mensuração dos dados foi utilizada a estatística descritiva (Mancuso et. al, 2018) para a análise qualiquantitativa de escala local e os dados estão apresentados no formato de tabelas e gráficos elaborados pelo Excel.

\subsection{Critério de inclusão e exclusão}

Para participar da pesquisa foram selecionados somente os alunos que participaram do programa no edital $\mathrm{N}^{\circ}$ 011/2010 (Pará, 2010), desenvolvido no Laboratório de Morfofisiologia Aplicada à Saúde da UEPA. 


\section{Resultados e Discussão}

O presente trabalho busca compreender a repercussão do PIBIC-EM. na escolha profissional dos alunos egressos do programa, através de um questionário que contém perguntas acerca da renda familiar, da participação em outras atividades acadêmico-científicas, do nível de formação atual, dos tipos de instituições de ES que foram cursadas e da importância do contato do ensino básico com o meio acadêmico. Além disso, o questionário também contém relatos dos participantes a respeito do tema central.

Nesse contexto, oportunidades voltadas para EB e ao ensino de ciências, as quais visam tornar a ciência interessante para os jovens, contribuem para redução das lacunas existentes no ensino regular. Essas iniciativas difundem saberes fundamentais para a compreensão e tomada de decisão, e para a participação política (Arantes \& Peres, 2015).

Quanto a renda salarial familiar 8 participantes (53\%), apresentam renda aproximada de até 1 salário-mínimo no período de aplicação do programa, enquanto que 6 participantes (40\%) apresentam até 2 salários-mínimos e 1 participante (7\%) apresentou mais de 5 salários-mínimos (Figura 2).

Figura 2. Renda familiar dos entrevistados no período do desenvolvimento do PIBIC-EM (N=15).

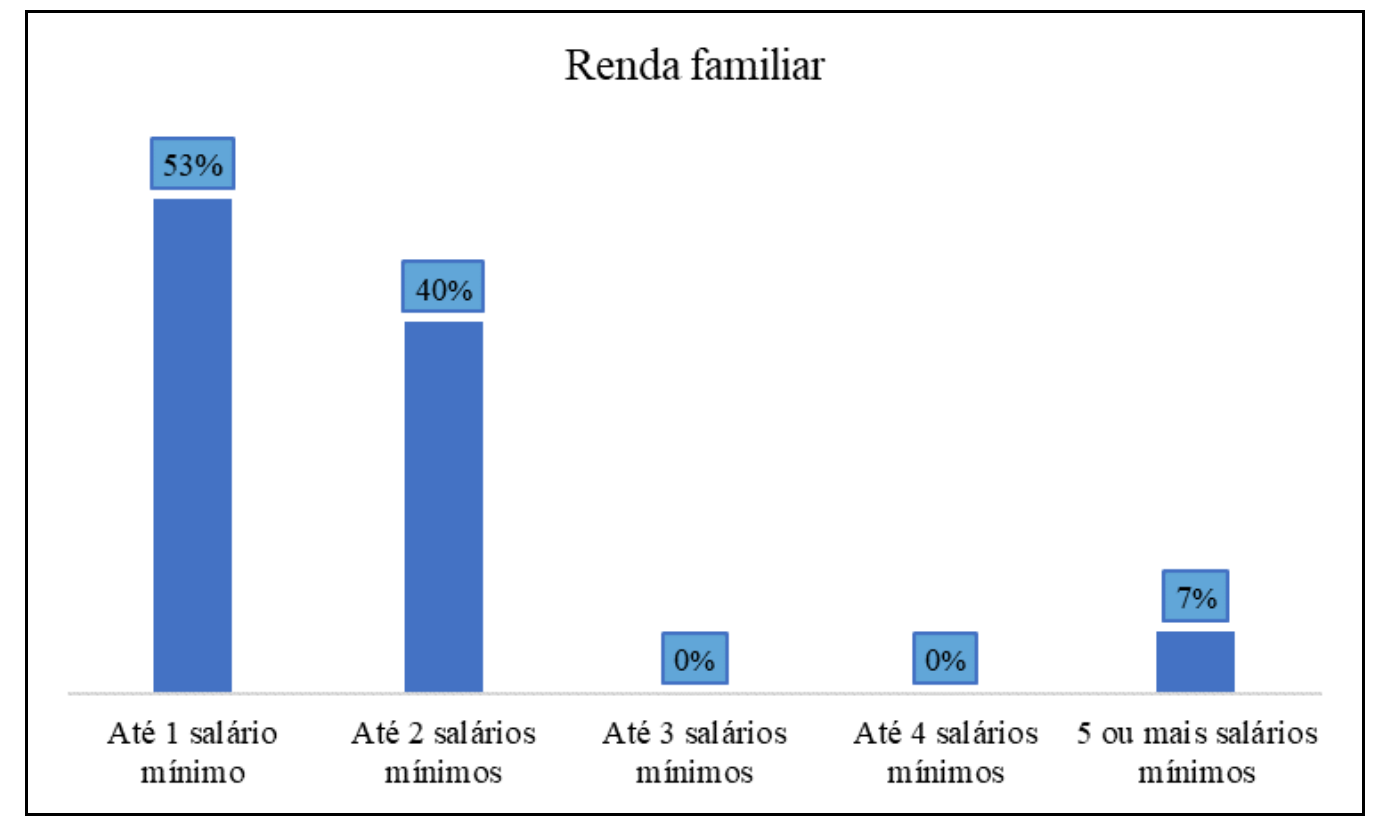

Fonte: Autores (2021).

De acordo com as Pesquisas Nacionais por Amostra de Domicílios (PNAD), em 2011, o Brasil atingiu o menor nível de desigualdade de renda, apesar desse contraste ainda existir. Essa redução ocorreu em função de uma maior diversidade de fontes de renda como: Trabalho, Previdência, Bolsa Família, Benefício de Prestação Continuada e Outras Rendas, configurando um efeito do crescimento trabalhista (Neri \& Souza, 2012).

Uma das vantagens do programa Bolsa Família, está relacionada à frequência escolar dos mais vulneráveis ou redução do abandono, o qual impacta positivamente na permanência destes na escola, visto que a maior desvantagem das taxas de escolarização está ligada ao nível de renda das famílias (Simões, 2014). Esse programa consiste na transferência de renda às famílias que se encontram abaixo da linha da pobreza, garantindo a segurança alimentar e, obrigando a permanência dos jovens na escola (Fahel, Canaan, Cabral \& Bahia, 2012). 
Além do Bolsa Família e de outros programas, o PIBIC-EM. contribui para o aumento dos níveis de permanência e conclusão de estudantes, de baixa renda e de escolas públicas, na EB, visto que esse programa é uma política pública de priorização da IC.

No questionário principal há um item relacionado à descrição da participação no programa, os relatos foram coletados para a análise qualitativa do estudo e são de grande importância para a avaliação do impacto do programa. Dentre eles, destacam-se:

Participei com muito entusiasmo do projeto. Desenvolveu em mim mais interesse pelo meio científico com ênfase na área das ciências biológicas. Com o projeto eu pude participar de práticas experimentais, a partir do conhecimento teórico favorecido pelo projeto. Ao final, tive a oportunidade de participar de uma feira científica. Todos os conhecimentos adquiridos no projeto e experiências marcaram a minha vida de estudante do ensino básico. Neste projeto também, eu pude ter a minha primeira experiência como um "cientista mirim" importante na decisão da minha profissão. (Participante 1).

Poder participar do Pibic Jr. foi muito bom, de forma que me ajudou muito na escolha da minha carreira profissional, sendo também um grande incentivo de estudo. (Participante 2).

Logo, acerca do item anterior, os participantes relatam que a participação do programa foi uma ótima experiência, contribuiu para a escolha da carreira profissional. Além disso, despertou o interesse pela pesquisa, ajudou nos estudos voltados ao vestibular e também para futuras séries do EM, proporcionou o primeiro contato com o ES, auxiliou na perda do medo de falar em público e proporcionou muito aprendizado.

De acordo com as respostas dos 15 participantes, nenhum participou de outro programa ou atividade acadêmicocientífica semelhante ao PIBIC-EM. (Figura 3). Isso torna evidente a importância dos Programas de ICJ ao tornar acessível os conhecimentos científicos aos jovens desfavorecidos, para que possam compreender a inovação, a experimentação, a produção desses conhecimentos e as suas aplicações, bem como o aumento de suas perspectivas de conclusão do EM (Arantes \& Peres, 2015). Portanto, é fundamental garantir o acesso às oportunidades de educação científica que ampliam as possibilidades de escolhas profissionais, podendo despertar o interesse pelo campo.

Figura 3. Frequência de participação em outras atividades acadêmico-científicas $(\mathrm{N}=15)$.

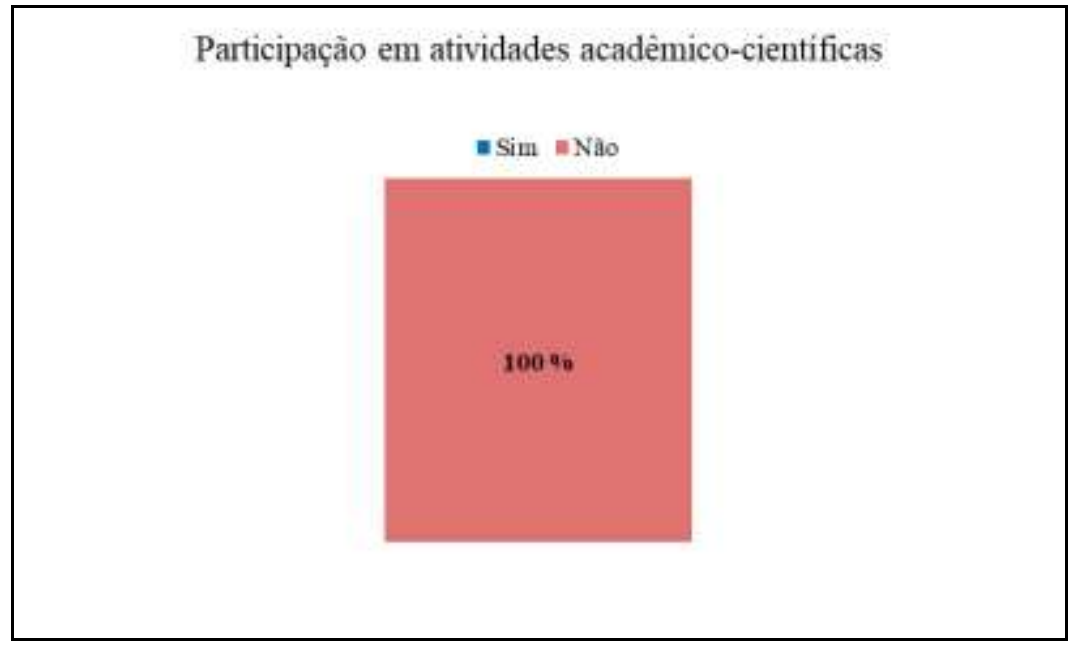

Fonte: Autores (2021).

Entre os participantes da pesquisa entrevistados, um total de 15 ex-alunos, 27\% que corresponde a 4 participantes, cursaram o Mestrado (em andamento ou concluído), 7\% (1 participante) cursou especialização, 27\% (4 participantes) chegaram até o nível superior completo, 20\% (3 participantes) cursaram o nível superior, mas não concluíram e $20 \%$ (3 
participantes) concluíram somente até o ensino médio completo. Portando, $81 \%$ dos participantes correspondem a um total de 12 indivíduos que ingressaram no ensino superior (Figura 4).

Figura 4. Percentual dos níveis de formação dos participantes na atualidade $(\mathrm{N}=15)$.

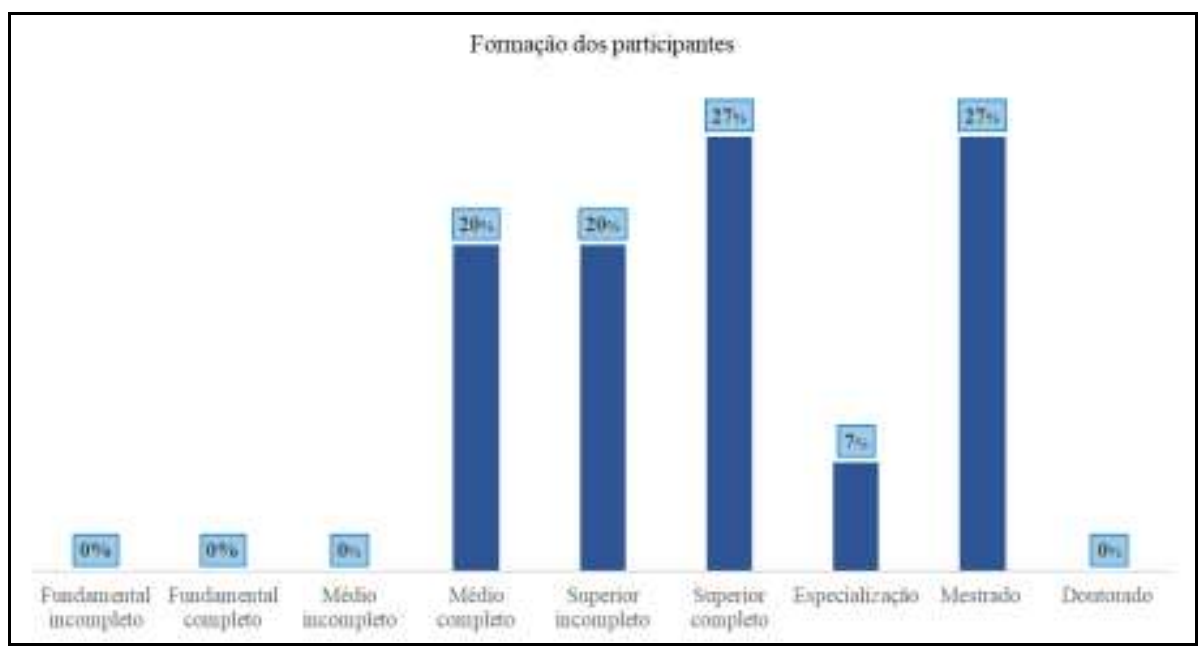

Fonte: Autores (2021).

O acesso ao ES é um dos temas conflituosos que perpassa o campo da educação, sendo, portanto, de grande importância debater acerca da democratização do acesso e da permanência. Nesse sentido, Souza e Brandalise (2017) afirmam que:

O sistema educacional favorece a conservação social, oferecendo condições de ascensão a níveis mais elevados da sociedade àqueles que já são favorecidos. Em geral, são poucos os alunos pobres que almejam o ingresso no ensino superior, pois historicamente os estudos universitários fazem parte da vida daqueles que não têm a necessidade de trabalhar para garantir seu sustento e de sua família. Em uma sociedade em que a educação superior é tida como um privilégio de poucos, a grande maioria dos estudantes abre mão do 'sonho' do ingresso em uma instituição de ensino superior em virtude da tradição histórica de exclusão (Souza \& Brandalise, 2017, p. 518).

Neste estudo houve indivíduos que não alcançaram o ES, 3 ex-alunos do programa concluíram somente até o ensino médio, sendo estes provenientes de escolas públicas e de baixa renda. Foi perguntado a eles: “Caso você não tenha ingressado em um curso de graduação, quais os motivos contribuíram para isso?" e as justificativas destes participantes foram: "Precisava trabalhar" (2 indivíduos) e "Engravidei" (1 indivíduo).

Portanto, muitos fatores influenciam para que os jovens não cheguem ao ES, tornando explícito os problemas estruturais da sociedade, como Silveira (2015) mostra que o perfil socioeconômico dos estudantes de escolas públicas, no Brasil, é muito distinto e isso revela consequências na qualidade de ensino, visto que a escolarização é precária e de baixa qualidade, evidenciando as desigualdades socioeducacionais, sendo, portanto, um dos maiores desafios a ser enfrentado.

Entretanto, um crescimento considerável vem ocorrendo no acesso de estudantes ao ES, provenientes de escolas públicas, e negros, historicamente excluídos, devido às propostas de políticas afirmativas e programas educacionais de incentivo a esse acesso, feitas pelo governo federal. E como exemplo de política de ação afirmativa, há a política de cotas que objetiva aumentar o número de alunos negros e/ou provenientes de escolas públicas no ensino superior (Souza \& Brandalise, 2017).

Além disto, nesse estudo é demonstrado que 12 indivíduos (81\%) alcançaram o ES e foram instigados pelo PIBICEM. que, portanto, pode ter contribuído para o ingresso desses alunos no Ensino Superior - que ainda pode ser influenciado por outros diversos fatores, tanto de forma positiva quanto negativa. Segundo dados divulgados pelo INEP (2020), em 2019 a 
taxa líquida de jovens entre 18 e 24 anos que estavam matriculados em cursos de graduação foi de 25,5\%. É evidenciado também que indivíduos de baixa renda e provenientes de escolas públicas almejam e vêm alcançando o ES, seja por meio de cotas ou de programas de incentivo.

Do total de 12 indivíduos que cursaram nível superior, 58\% (7 participantes) estudaram em instituições públicas, enquanto $8 \%$ (1 participante) em instituições privadas e 33\% (4 participantes) em instituições privadas com uso de financiamento (Figura 5).

Figura 5. Caracterização das instituições de ensino superior.

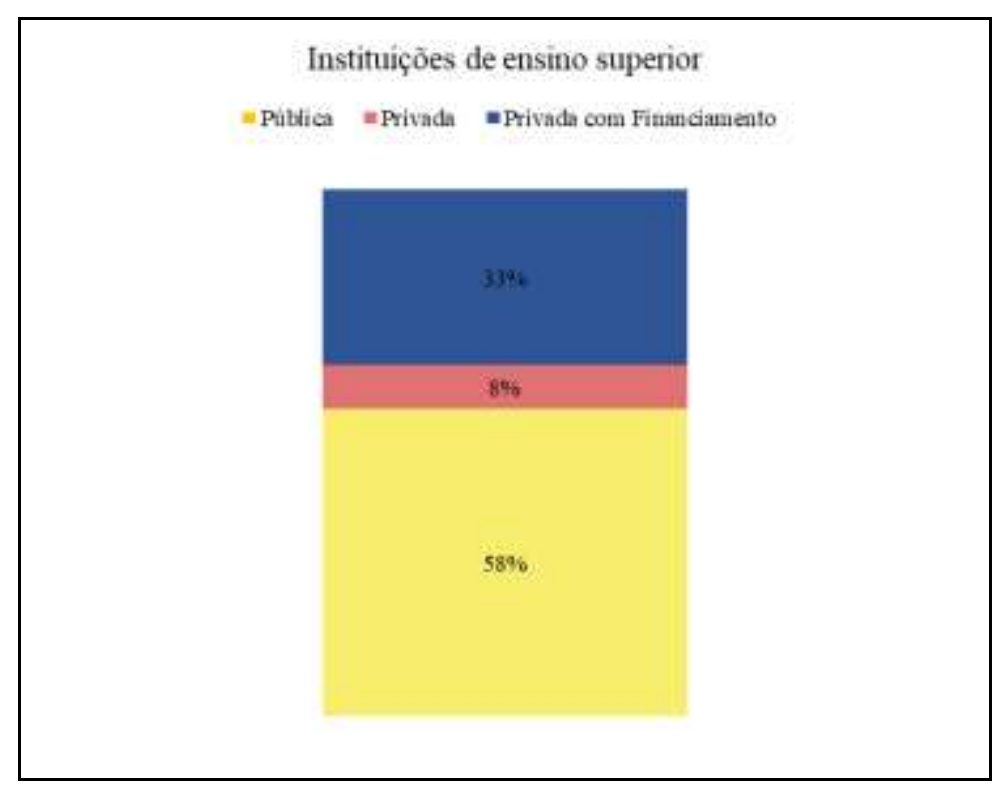

Fonte: Autores (2021).

O setor privado veio adquirindo significativa presença no ES, devido à incapacidade do setor público. O setor privado possuía 58,4\% dos alunos matriculados no ES, na década de 90 e, em 2013, o total de alunos na graduação presencial, chegou a 73,5\%. Já em 2016, 75,3\% estavam matriculados na rede privada, enquanto 24,7\% na rede pública, segundo o MEC e o Instituto Nacional de Estudos e Pesquisas Educacionais Anísio Teixeira (INEP). Houve diminuição no valor das mensalidades, devido ao aumento da concorrência, possibilitando o ingresso de alunos de baixa renda (Gomes, Taylor \& Saraiva, 2018).

Apesar da expansão do ES privado, nesse trabalho, evidenciamos que 58\% dos participantes estudaram em instituições públicas e $41 \%$ em instituições privadas. Contudo, dos 5 alunos que foram para rede privada, todos possuíam entre 1 a 2 salários-mínimos, e destes, 4 tiveram incentivo de programas de financiamento do Governo Federal.

O Programa Universidade para Todos (PROUNI), visando a democratização do ensino e de justiça social, foi criado pela Medida Provisória n. 213/2004 e institucionalizado pela Lei n. 11.096, de 13 de janeiro de 2005 (Lei n.11.096, 2005), destinado a conceder bolsas de estudos integrais e parciais a estudantes de baixa renda, com deficiências, autodeclarados afrodescendentes, indígenas e professores da escola básica pública, para frequentarem instituições privadas de educação superior. Em 2012, o PROUNI concedia um milhão de bolsas e 553 mil novas inscrições para uma das suas 195 mil bolsas disponíveis; para custear a mensalidade do aluno (Prestes, Jezine \& Scocuglia, 2012).

Dessa maneira, o PROUNI e os demais programas de financiamento estudantil vem contribuindo para o acesso de estudantes, pobres da rede pública, ao ES. Isso evidencia a grande importância desses programas, visto que eles vêm aumentando o ingresso desses estudantes e democratizando o ensino. 
A Figura 6 mostra a importância da participação no programa para a escolha profissional, onde 10 participantes (67\%) afirmaram que a participação no programa foi importante nas suas escolhas, uma vez que esse contato serviu como incentivo na busca por um curso de graduação para área de concentração do programa.

Em contrapartida, 4 participantes (27\%) afirmaram que essa participação não influenciou em suas escolhas, visto que não seguiram carreira na área de concentração do programa. Apenas 1 indivíduo (7\%) alegou que a participação no programa influenciou parcialmente em sua escolha, posto que o mesmo seguiu carreira na área de Ciências Biológicas e da Saúde, mas ressalta que o programa não teve influência em sua escolha.

Figura 6. Importância da participação no programa para a escolha profissional

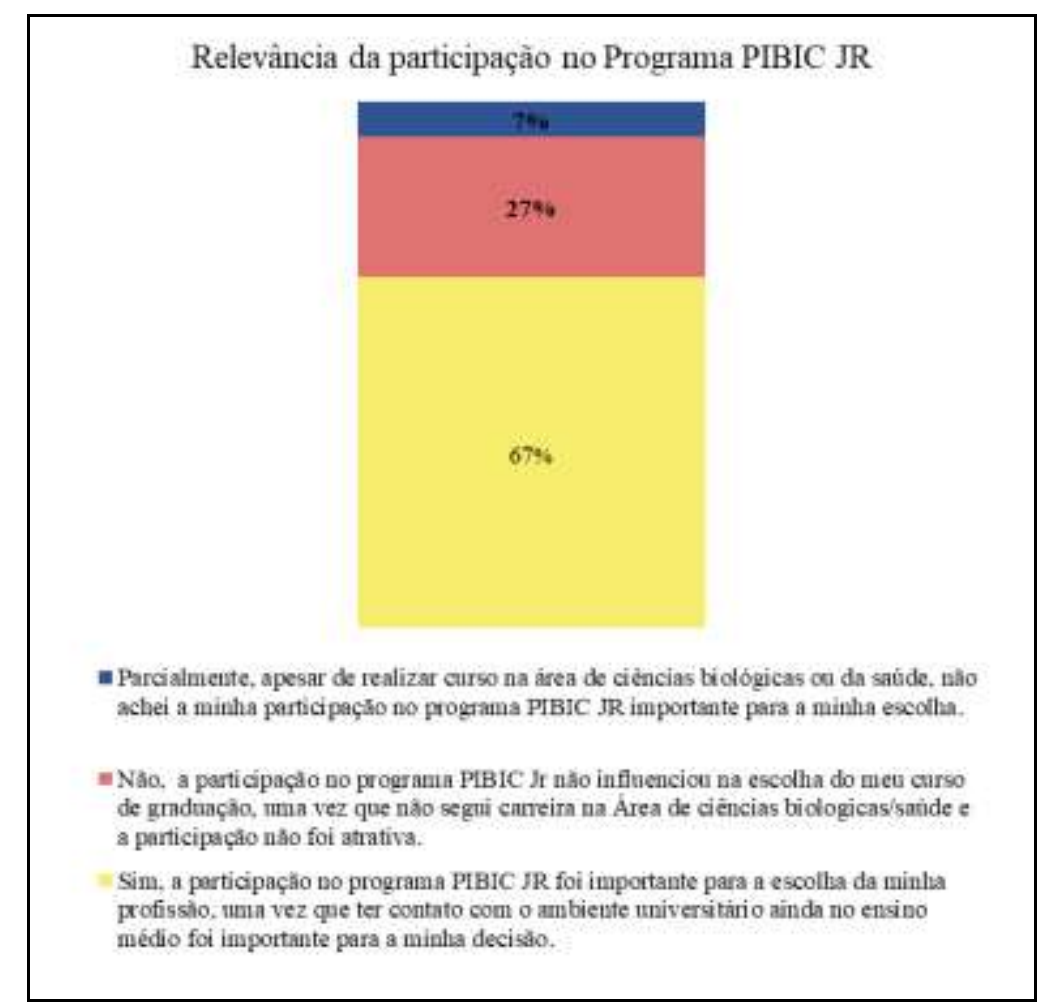

Fonte: Autores (2021).

Nora, Almeida e Cardoso (2019) relatam em seu estudo que contou com a participação de 15 alunos bolsistas - que a maioria dos participantes do PIBIC-EM ingressaram na graduação na área de concentração do programa (Geografia), além de áreas como economia e medicina veterinária, o que evidencia a relevância da participação de estudantes em programas de IC, pois de fato influencia significativamente na escolha profissional.

A Figura 7 evidencia que todos os participantes concordam que o contato de alunos com o ambiente acadêmico durante o ensino básico (fundamental e médio) é de grande importância para o desenvolvimento pessoal, autonomia, e consequentemente, a escolha da carreira profissional. 
Figura 7. A importância do contato dos alunos do ensino básico com o meio acadêmico.

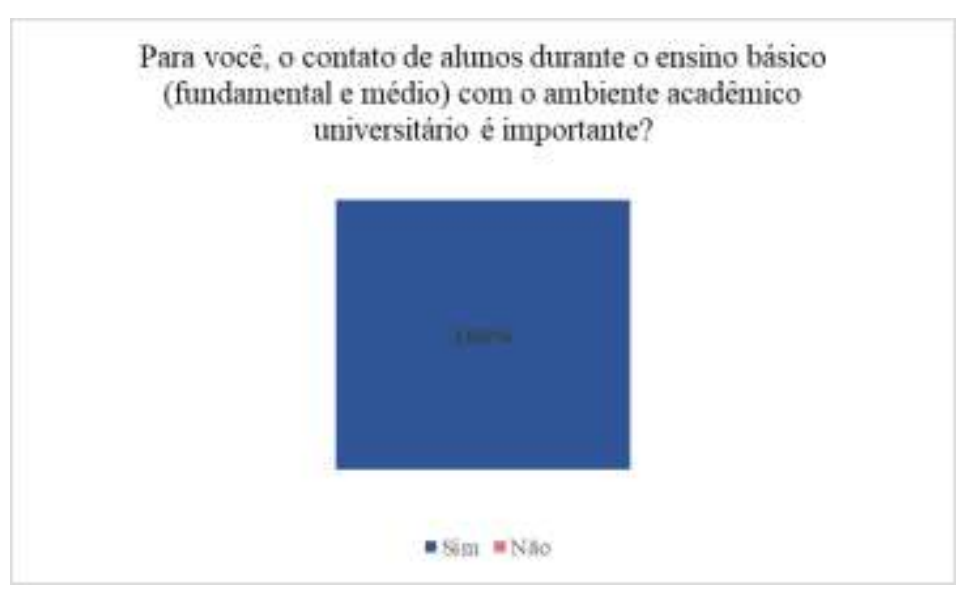

Fonte: Autores (2021).

A participação na iniciação científica é responsável por promover aprendizagem ativa, sendo uma importante ferramenta didática que envolve o aluno na construção do conhecimento (Tolfo, 2020). Além disso, essa prática e, principalmente, o envolvimento da pesquisa no ensino básico são importantes para desenvolver habilidades essenciais nos alunos para o seu desenvolvimento pessoal, e contribuem ainda para mudanças necessárias na prática docente (Melo, 2020).

Segundo Amâncio e Neves (2003) a vivência do estágio para os alunos, possui um significado único para cada um e isso repercute de formas distintas em suas vidas. No estudo das autoras, é revelado na fala de alguns participantes que tal vivência nos laboratórios foi de grande relevância, além de muitos citarem a autonomia, autoconfiança e independência, como habilidades adquiridas.

Outra vivência semelhante foi denotada por Heck et. al (2012), na qual a IC no EM gerou frutos significativos. Antes da entrada no programa cerca de $75 \%$ dos alunos não atingiam a média escolar para aprovação em testes de conhecimentos gerais em fisiologia, bioquímica e biologia. Após 6 meses da entrada no Projeto, foi registrado que 95\% dos participantes atingiram conceitos máximos nesta mesma avaliação. Além disso, aqueles que permaneceram por mais tempo no programa demonstravam melhores resultados, proveniente de um processo contínuo de aprendizado.

De acordo com Zenorini e Santos (2010) quando o indivíduo atribui valor às metas e enxerga nas suas ações possibilidades de atingir seus objetivos, ele passa a ter comportamentos voltados para a realização das tarefas. Essa condição motivacional está diretamente relacionada ao desempenho do estudante, sendo, portanto, de grande importância para o enfrentamento dos desafios que surgirão no decorrer da pesquisa.

A participação no Programa permite o enfrentamento de medos, como o de falar em público, de criar hábitos de leituras científicas, visto que esta precisa ser significativa, permitindo uma interpretação (Santos, 2011). Além disso, segundo Lima (2004), esse hábito precisa estar vinculado à escrita, pois esta contribui para a reflexão, organização das ideias e posicionamento do aluno, podendo concordar ou não com determinado autor.

Ainda sobre o estudo de Santos (2011), a aluna bolsista que experienciou a ICJ, passou a ter mais atenção nas leituras, responsabilidade para com os experimentos, capacidade de produzir e organizar argumentos em seus relatórios, autoconfiança para apresentações em eventos, dentre outras. Portanto, as qualidades e habilidades que foram proporcionadas à aluna foram inúmeras, as quais colaboraram para a formação da estudante e pode servir de apoio para a vida acadêmica.

Para responder o último item do questionário, foi solicitado aos participantes que justificassem suas respostas acerca da importância do contato vivenciado durante o ensino básico com o ambiente acadêmico universitário (Figura 7). Todos afirmaram em seus relatos que esse contato foi importante, e alguns destes serão destacados: 
"Acredito que o ambiente acadêmico universitário deve estar em contato permanente com a sociedade, para promoção de conhecimento e das profissões atreladas à criação deste. Pela natureza da atividade acadêmica, o contato com estudantes do ensino básico é fundamental para mostrar possibilidades de carreira, assim como promover uma aceleração e aprofundamento de seu aprendizado" (Participante 3).

“É importante pois durante essa fase (adolescência) é onde se tem muitos questionamentos de qual área seguir no futuro, o PIBIC se torna de grande importância para sanar essas dúvidas” (Participante 4).

"É importante pois promove um senso visionário a respeito da importância de evolução educacional (Fundamental, médio, graduação dentre outros), no caso do PIBIC JR. possibilitou (relato pessoal) a escolha do meu curso de graduação e as informações obtidas no programa foram de fundamental auxílio" (Participante 5).

"O ensino básico muitas vezes parece estar distanciado da realidade do ensino superior, atividades que aproximem estes ambientes são ótimas formas de introduzir os alunos do ensino básico em formação acadêmica, visto que muitos alunos possam se sentir desnorteados na escolha de uma profissão para o futuro. Além de oferecer também uma oportunidade de extensão para as atividades acadêmicas dos cursos, onde alunos e professores possam contribuir com a comunidade a fora da universidade” (Participante 6).

"Além da importância de estar em contato com as áreas de conhecimento pleiteadas, a fim de testar compatibilidade, este contato com ambiente acadêmico ajuda a quebrar imagens romantizadas do que seria a Universidade e se realmente é este caminho que gostaríamos de seguir" (Participante 7).

Diante das falas dos participantes dessa pesquisa e dos relatos de outros que experienciaram a ICJ, demonstrado em distintos trabalhos, é possível perceber o quanto o PIBIC-EM. é relevante para a escolha profissional e para o crescimento pessoal, visto que apesar de alguns não seguirem a área de concentração do programa, estes desenvolvem habilidades que lhes servirão tanto para a vida acadêmica, quanto profissional.

Contudo, é importante frisar que há necessidade de mais investimentos e que o Programa ainda é pouco divulgado, podendo ser extinto, uma vez que ao longo dos tempos está ocorrendo uma diminuição da promoção de bolsas e da utilização destas, ademais, possui baixa adesão por parte dos orientadores, devido às condições limitadas de trabalho e ao pouco tempo disponível destes, e há a questão das escolas estaduais e municipais que, geralmente, possuem infraestrutura precária (Oliveira \& Bianchetti, 2018).

Pinzan e Lima (2014) concordam com o exposto acima e afirmam também que:

Outro fator a ser considerado, não somente aos professores universitários, mas principalmente aos da Rede Básica, é a questão do tempo, que professores lutam entre o planejamento das aulas, correção de trabalhos, reuniões pedagógicas e vida pessoal, ou seja, não há incentivos para que os professores da escola básica tenham condições mínimas para pesquisar, e mesmo diante de vários esforços para realizar a pesquisa, há permanência de certo pensamento da inferioridade do trabalho produzido. (Pinzan \& Lima, 2014, p. 6).

Desse modo, é evidente a necessidade de mais incentivos governamentais através de políticas públicas para que se consiga ampliar o acesso de alunos à IC durante o ensino básico e, de capacitações para os docentes atrelados ao programa, visto que esses possuem muitas limitações. Ademais, é indispensável pensar em formas de implementar a IC no ensino básico, de maneira que contemple a grande maioria dos estudantes, e reforçar que apesar de todas as dificuldades, o programa ainda existe e é uma forma de proporcionar e disseminar conhecimento.

Por fim, além das problemáticas já explicitadas, ainda há o desconhecimento dos Programas de Iniciaçao Científica Jr por parte dos professores e das escolas, o que problematiza ainda mais o acesso à IC. Isso também é consequência do distanciamento entre EM e ES que ainda prevalece. Segundo Costa e Zompero (2017, p.22) “ainda existem instituições escolares que permanecem no ostracismo, e essa inércia educacional contribui negativamente para a não propagação da pesquisa e da Iniciação Científica no Ensino Médio”. 


\section{Conclusão}

O trabalho demonstrou que a maioria dos participantes alcançaram o ensino superior público e optaram por cursos da área de Ciências Biológicas e da Saúde, ou seja, na mesma área onde cumpriram o programa de PIBIC-EM. Além disso, nos relatos é perceptível que o Programa serviu como estimulador para a escolha da carreira profissional. Logo, o programa contribui para que indivíduos de baixa renda almejem o ES.

Os dados revelam também uma sensível elevação na inserção de alunos no ensino privado através do uso de programas de financiamento, evidenciando a importância desses programas para a democratização do ensino e para que muitos jovens de baixa renda consigam ingressar no ES.

Portanto, o programa de PIBIC-EM. possui impacto positivo na vida daqueles que vivenciam a iniciação científica, oportunizando uma experiência única e rica de conhecimentos, adquiridos e produzidos, e aprendizados, oferecendo um preparo não somente para a vida acadêmica, se essa for optada, mas para a vida em si, diante de todo o aprendizado adquirido no decorrer do programa.

\section{Referências}

Aaker, D. A., Kumar, V., \& Day, G. S. (2001). Marketing research, 7th. John Wiley Operations Research \& Sons, 51(4), pp. 509-518, New York.

Amâncio, A. M., \& Neves, R. M. C. (2003). Conhecendo seus próprios talentos: jovens de escolas públicas em instituições de pesquisa no Rio de Janeiro. Educação e Sociedade, 24 (83), pp. 645 - 658. < https://www.scielo.br/j/es/a/HXwZDh7SG6SprRRbY9SrCtv/?format=pdf\&lang=pt >

Arantes, S. L. F., \& Peres, S. O. (2015). Programas de iniciação científica para o ensino médio no Brasil: educação científica e inclusão social. Revista Pesquisas e Práticas Psicossociais, $10(1), \quad$ pp. $\quad 37-54 . \quad$ http://pepsic.bvsalud.org/scielo.php?script=sci_arttext\&pid=S1809$89082015000100004 \& \operatorname{lng}=$ pt\&nrm=iso >

Conceição, A. J. (2012). Contribuições do programa de iniciação científica júnior na universidade estadual de londrina (UEL): a formação de um habitus adequado ao campo científico. Dissertação de Mestrado em Políticas Públicas, Universidade Estadual de Maringá, Maringá, PR, Brasil. < http://repositorio.uem.br:8080/jspui/handle/1/4079>

Conselho Nacional de Desenvolvimento Científico e Tecnológico. (2008). Anexo V com nova redação dada pela Resolução Normativa 017/2006 Iniciação científica júnior: norma específica (Seção: 1, p. 8). Publicada no Documento Oficial da União de 08 de outubro de $2008 . \quad<$ https://www.ifpb.edu.br/prpipg/pesquisa/Normas\%20e\%20Resolucao/rn-017-06-iniciacao-cientifica-junior.pdf >

Costa, W. L., \& Zompero, A. F. (2017). A Iniciação Científica no Brasil e sua propagação no Ensino Médio. Revista de Ensino de Ciências e Matemática, $8(1)$, pp. 14-25. https://doi.org/10.26843/rencima.v8i1.988

Fahel, M., Canaan, M., Cabral, B., \& Bahia, M. (2012). O impacto do Bolsa Família na inclusão educacional: análise da matrícula escolar em Minas Gerais. Ser Social, 14(30), pp. 98-126. https://doi.org/10.26512/ser_social.v14i30.12831

Gomes, V., Taylor, M. L. M., \& Saraiva, E. V. (2018). O Ensino Superior no Brasil -Breve Histórico e Caracterização. Ciência \& Trópico, 42(1), pp. 127-152. < https://periodicos.fundaj.gov.br/CIC/article/view/1647>

Heck, T. G., Maslinkiewicz, A., Sant'helena, M. G., Riva, L., Lagranha, D., Senna, S. M., Dallacorte, V. L. C., Grangeiro, M. E., Curi, R., \& Bittencourt, P. I. H. (2012). Iniciação científica no ensino médio: um modelo de aproximação da escola com a universidade por meio do método científico. Revista Brasileira de Pós-Graduação, 8(2).< https://doi.org/10.21713/2358-2332.2012.v8.245 >

Instituto Nacional de Estudos e Pesquisas Educacionais Anísio Teixeira - Ministério da Educação. (2020). Censo da Educação Superior 2019. < https://www.gov.br/inep/pt-br>

Lei n. 10.172/01 (2001). Plano Nacional de Educação [objetivos e metas para a educação superior]. Brasília. < http://www.planalto.gov.br/ccivil_03/leis/leis_2001/110172.htm >

Lei n. 11.096, de 13 de janeiro de 2005 (2005). Institui o Programa Universidade para Todos - PROUNI. Brasília. < http://www.planalto.gov.br/ccivil_03/_ato2004-2006/2005/lei/111096.htm >

Lei Complementar n. 061, de 24 de julho de 2007 (2007). Institui a Fundação Amazônia Paraense de Amparo à Pesquisa - FAPESPA - e dá outras providências. Diário Oficial do Estado. Belém. < http://www.fapespa.pa.gov.br/sites/default/files/Leis_da_FAPESPA_-_Consolidacao_via_ProJur_25-0712_0.pdf >

Lima, V. M. R. (2004). A escolha da pesquisa como princípio educativo. Ciência e Letras, n. 36, pp. 151-169.

Mancuso, A. C. B., de Jezus Castro, S. M., Guimarães, L. S. P., Leotti, V. B., Hirakata, V. N., \& Camey, S. A. (2018). Estatística descritiva: Perguntas que você sempre quis fazer, mas nunca teve coragem. Clinical \& Biomedical Research, 38(4).

Massi, L., \& Queiroz, S. L. (2010). Estudos sobre iniciação científica no Brasil: uma revisão. Cadernos de Pesquisa, 40(139), pp. 173-197. < https://doi.org/10.1590/S0100-15742010000100009> 
Melo, M. G. de A. (2020). Iniciação Cientifica no interior da Amazônia: promovendo alfabetização científica e tecnológica com alunos do ensino básico de um clube de Ciências. Research, Society and Development, 9(8), e775986363. < https://doi.org/10.33448/rsd-v9i8.636 >

Moraes, G. C., Soppa, L P., Umbelino, G. K., \& Vieira, C. H. (2013, setembro). A iniciação científica Júnior - o que dizem os alunos. Anais do XI Congresso Nacional de Educação-EDUCERE, II Seminário Internacional de Representações Sociais, Subjetividade e Educação-SIRSSE e IV Seminário Internacional sobre Profissionalização Docente-SIPD/Cátedra UNESCO, Curitiba, PR, Brasil: PUCPR, 11. < https://educere.bruc.com.br/CD2013/pdf/8097_6928.pdf >

Neri, M. C., \& Souza, P. H. G. F. (2012). A década inclusiva (2001-2011): desigualdade, pobreza e políticas de renda (p.44). Brasília: IPEA. < http://repositorio.ipea.gov.br/handle/11058/4639>

Nora, G. D., Almeida, M. A., \& Cardoso, R. (2019). O PIBIC Ensino Médio Geografia e a Educação Básica: a experiência da utilização de óleo residual na fabricação de sabão líquido. Revista Brasileira de Educação em Geografia, 9(18), pp. 304-320.

Oliveira, A., \& Bianchetti, L. (2018). Iniciação Científica Júnior: desafios à materialização de um círculo virtuoso. Ensaio: Avaliação e Políticas Públicas em Educação, 26(98), pp. 133-162. < https://doi.org/10.1590/S0104-40362018002600952 >

Parâmetros Curriculares Nacionais para o Ensino Médio - Bases Legais (2000) (p.10). Brasília: MEC/SEMTEC. Recuperado em 15 de janeiro, 2021, de < http://portal.mec.gov.br/seb/arquivos/pdf/blegais.pdf >

Pará, Edital de Programa de bolsas de iniciação científica júnior para o centro de ciências (Planetário) da Universidade do Estado do Pará nº11/2010. Belém, PA, Brasil: FAPESPA, n. 011, pp. 1-5, 2010.

Pereira A. S. et al. (2018). Metodologia da pesquisa científica. [free e-book]. Santa Maria/RS. Ed. UAB/NTE/UFSM.

Pinzan, M. E., \& Lima, A. P. (2014, outubro). Iniciação científica na educação básica: uma possibilidade de democratização da produção científica. Anais do IX EPCT-Encontro de Produção Científica e Tecnológica, Campo Mourão, PR, Brasil: UNESPAR, 9. < http://www.fecilcam.br/nupem/anais_ix_epct/PDF/TRABALHOS-COMPLETO/Anais-CH/10.pdf >

Prestes, E. M. T., Jezine, E., \& Scocuglia, A. C. (2012). Democratização do ensino superior brasileiro: o caso da Universidade Federal da Paraíba. Revista Lusófona de Educação, 21(21), pp. 199-218. < https://revistas.ulusofona.pt/index.php/rleducacao/article/view/3088

Santos, J. K. R. (2011). Oportunidades de aprender sobre pesquisa na iniciação científica júnior de uma bolsista no clube de ciências da UFPA. Dissertação de Mestrado em Educação em Ciências e Matemática, Instituto de Educação Matemática e Científica, Universidade Federal do Pará, Belém, PA, Brasil. < http://repositorio.ufpa.br/jspui/bitstream/2011/4538/1/Dissertacao_OportunidadesAprenderPesquisa.pdf >

Silveira, Z. S. (2015). Formação científica no nível médio de ensino: primeiras aproximações. Boletim Técnico do Senac, 41(1), pp. 36-5.

$<$ https://www.bts.senac.br/bts/article/view/55 >

Simões, A. (2014). Acesso e Evasão na Educação Básica: as perspectivas da população de baixa renda no Brasil. Brasília: MDS. 2021, de < https://bit.ly/3ikQWnG >

Souza, A. C., \& Brandalise, M. A. T. (2017). Política de cotas e democratização do ensino superior: a visão dos implementadores. Revista Internacional de Educação Superior, 3(3), pp. 515-538. https://doi.org/10.22348/riesup.v3i3.7763

Tolfo, C. (2020). A Iniciação Científica como instrumento de promoção da aprendizagem ativa dos alunos em sala de aula. Research, Society and Development, 9(8), p. e977986889. <https://doi.org/10.33448/rsd-v9i8.6889>

Zenorini, R. P. C., \& Santos, A. A. A. (2010). Escala de metas de realização como medida da motivação para aprendizagem. Revista Interamericana de Psicologia, 44(2), pp. 291-298. < https://www.redalyc.org/pdf/284/28420641010.pdf > 